\title{
INTRAMUSCULAR ABDOMINAL WALL ENDOMETRIOSIS, AN UNUSUAL FINDING FOR GENERAL SURGEON
}

\author{
ALIN MIHEŢIU ${ }^{1}$, DAN BRATU ${ }^{2}$, OANA POPESCU ${ }^{3}$ \\ 1,2,3 “Lucian Blaga” University of Sibiu, 1,2 Sibiu County Emergency Clinical Hospital
}

Keywords: endometriosis, abdominal wall, cesarean section, recurrence
Abstract: Defined as the ectopic development of uterine tissue outside the uterine cavity, endometriosis is an increasingly common condition that can lead to various complications from chronic pain syndrome, infertility, obstruction due extrinsic compression to malignancy of endometriosis foci. Extrapelvic positioning of endometriosis is rare, diagnosis can be difficult both clinically and imaging, and treatment does not always ensure the absence of recurrences.

\section{INTRODUCTION}

Endometriosis was first described by Karl Freiherr von Rokitansky in 1860.

It is most common in the pelvis, ovaries, Douglas pouch, uterine ligaments, or posterior cul-de-sac, but it may also have extrapelvic locations in the abdominal wall, umbilical cord, ileum, colon, vulvar, or sacs of inguinal or femoral hernia.

The incidence of this condition in childbearing age women is between $5-15 \%$, localizations in the abdominal wall being rare.

The appearance of endometriosis implants in the abdominal wall is related to surgery, most commonly with cesarean section, the tumours usually appear in the postoperative scars.

The appearance of a tumour in the abdominal wall, in the proximity of a scar, in the lower abdomen and especially the painful manifestations in relation to the menstrual cycle, indicates the suspicion an outbreak of endometriosis.

The treatment is a multimodal one, but surgical excision remains the main choice as therapy, especially since there is also the risk of malignant transformation. $(1,2,3,4)$

\section{CASE REPORT}

A 34-year-old patient presents a left paramedian tumour in the lower abdomen, first discovered two years ago. The patient is known to have epilepsy, cesarean section (Pfannenstiel incision) 8 years ago.

For about a year and a half, the patient complains of pain related to the menstrual cycle in the newly formed nodule, pain that for about 3 months is no longer cyclical but continuous.

On clinical examination, in left paramedian lower abdomen, in the lower third of the left rectus abdominal muscle and at about $8 \mathrm{~cm}$ from the post-cesarean scar, a tumour located deep in the thickness of the muscular structures was highlighted. The formation was sensitive to palpation with relatively regular edges, hard consistency with the size around of $4 / 3 \mathrm{~cm}$. No other changes were found at clinical examination of the abdomen.

Lab tests were without pathological values, in normal limits.
Abdominal ultrasound shows in the thickness of the left side of rectus abdominal muscle a hypoechoic formation, inhomogeneous with microcalcifications, well vascularized, well delimited with dimensions of $3 / 1.1 / 2.2 \mathrm{~cm}$, without exceeding the muscle fascia.

Anamnestic and clinical examination raises the suspicion of parietal endometriosis.

Figure no. 1. Ultrasound appearance - tumour in the thickness of the rectus abdominal muscle

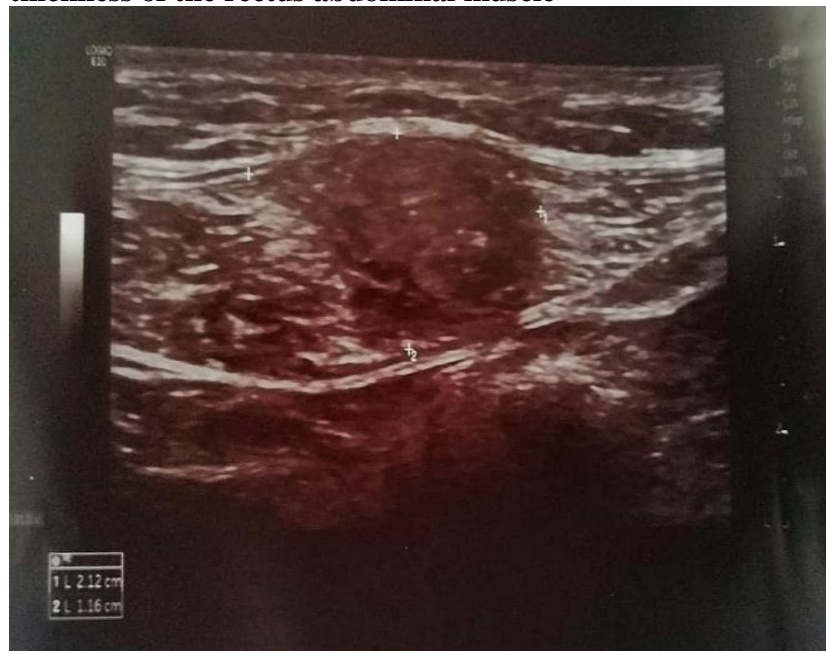

Surgery was performed under spinal anesthesia, posterior to the anterior sheath of the left rectus abdominal muscle, medial to the epigastric vessels (that are intercepted and preserved) in muscle thickness, adherent to muscle fibers a tumour of about $4 / 3 / 3 \mathrm{~cm}$, was highlighted.

The tumour was completely removed with safety limits included.

Myoraphy, rectus abdominal aponeurosis closure and skin suture were performed.

On the section, yellow-grey looking piece

The evolution was favourable, the patient being discharged the next day.

${ }^{1}$ Corresponding author: Alin Mihețiu, B-dul Corneliu Coposu, Nr. 2-4, Sibiu, România, E-mail: alin_mihetiu@ yahoo.com, Phone: +40751 619292 Article received on 22.10.2020 and accepted for publication on 26.02.2021 


\section{CLINICAL ASPECTS}

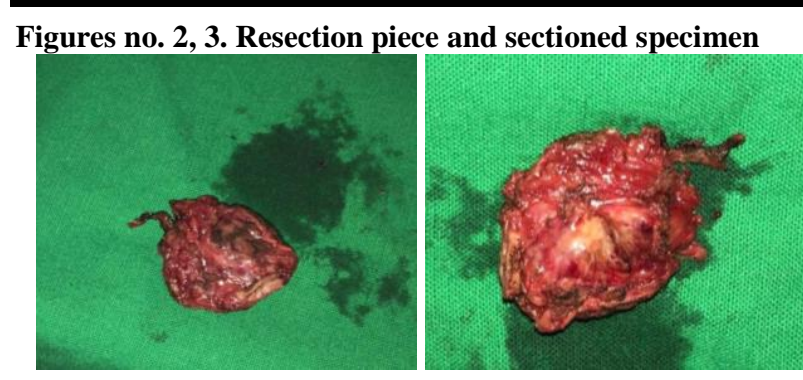

Figures no. 4, 5. Postoperative aspect in evolution (the dotted line coincides with the post-cesarean scar)

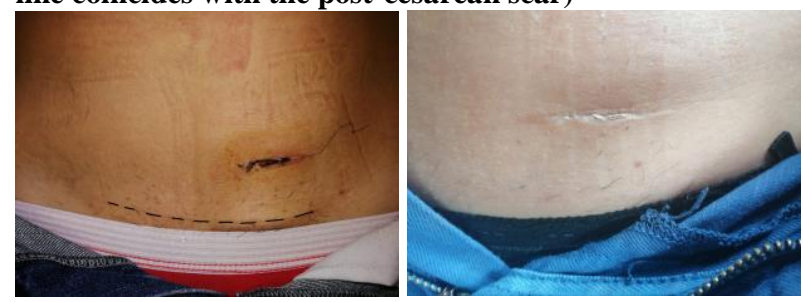

The anatomopathological result showed fragments of connective tissue and striated muscle with chronic inflammatory changes (gigantocellular reaction, macrophage and histiocytic reaction) around some endometriotic foci (glands and endometrial stroma), hematological infiltrates with the presence of hemosiderin pigment. The histological diagnosis was parietal endometriosis. recurrence.

Subsequent surgical checks showed no signs of local

\section{DISCUSSIONS}

Endometriosis is defined as the ectopic spread of functional endometrial glans and stroma.(5)

In 1860, von Rokitansky described the first case of endometriosis as "sarcoma". In 1899, Russel first identified and described the existence of endometrial tissue in the ovary.(5)

It affects between $5-15 \%$ of women of reproductive age. The distribution of endometriosis can be pelvic or extrapelvic. At the pelvic level, foci of endometriosis are found in the bottom of the Douglas pouch, ovaries, in the reflection of the peritoneum on the pelvic organs and in the uterine ligaments.

Extrapelvic localizations are rare and may involve the abdominal wall, umbilicus, small intestine, appendix, large intestine, kidneys, pleura, lungs, or central nervous system. (5)

Endometriosis of the abdominal wall with functional endometrial tissue was first described in 1950.

Frequently this localization associates surgical interventions in the background with an incidence between 0.03 $1.08 \% .(6,7)$

The vast majority of cases of parietal endometriosis have a history of gynecological surgery, usually after hysterectomy, cesarean section or hysteroscopy.

Thus, it is considered that the risk of endometriosis in the scar abdominal wall is $2.7 \%$ after obstetric interventions, $1.5 \%$ after gynecological interventions and $0.6 \%$ after laparoscopic interventions.

The location of endometrial tumours in the abdominal wall is common in the postoperative scar (especially in their extremities) or in their vicinity.

Parietal locations distant from postoperative scars are a rare finding. Also, parietal endometriosis has as favourite place of development the subcutaneous cellular tissue, the placement strictly intramuscularly or without the involvement of the peritoneum is not frequently encountered. $(1,2,8,9,10)$

As a preventive measure, before abdominal closure it is recommended to isolate the incision with sterile fields and abundant lavage with saline solutions to limit the risk of intraoperative contamination.(8)

Surgery is not the only way to develop parietal endometriosis, the literature also describes cases of de novo abdominal wall damage. Also, not only gynecological surgeries have the potential for parietal endometriosis, cases being described after laparoscopic treatment of inguinal hernia, appendicitis or colorectal surgery. $(11,12,13)$

The etiopathogenesis of this condition is still unclear and controversial, there are several theories that try to explain how the outbreaks of endometriosis appear, spread and proliferate.

The implantation theory - considered basically a secondary implantation either by retrograde menstruation or iatrogenic, surgical. However, menstrual reflux or gynecological surgery does not always progress to endometriosis, the explanation being that the immune system recognizes and destroys endometrial cells outside the uterus. A dysfunction of the immune system (with the genetic component) explains why yet ectopic endometrial tissue implants develop.(9)

The theory of metaplasia (Meyer) describes the spread of endometrial cells in the embryonic stage and their migration along the coelomic cavity.(6)

Lymphatic (metastatic) theory explains the appearance of endometrial structures in atypical places: brain, lung, lymph nodes, myocardial tissue, etc.(14)

Alcohol consumption, heavy menstrual cycle, obstructions in the evacuation of the menstrual cycle (Müllerian abnormalities), prolonged exposure to estrogen and dioxin are incriminating factors in the occurrence of endometriosis.

Clinically, parietal endometriosis may have nonspecific symptoms, with suspicion of endometriosis rising when the triad described by Esquivel is present: tumor, catamenial pain, and history of cesarean section.(15)

If they are associated with dysmenorrhea or heavy menstrual or intermenstrual bleeding, then the diagnosis can be oriented from the clinical-anamnestic examination phase.

Superimposed pain on the menstrual cycle is the main symptom that guides the clinician, but it is not always cyclical, sometimes having a permanent character and making the diagnosis more difficult.

The differential diagnosis is made with desmoid tumors, granulomas, fetal necrosis, lipomas, hernias, metastatic secondary determinations. CT or MRI.

Imaging diagnosis is usually performed by ultrasound,

In ultrasound, the vast majority of nodules appear as decrete solid masses, with a lower echogenicity than adipose tissue or compared to the neighboring musculoskeletal planes. The proximity to a postoperative scar or history of endometriosis guides the diagnosis.(16,17,18)

MRI provides superior data to CT examination, detecting smaller formations, periendometrial vascularization and the boundary between the muscular, aponeurotic planes or the degree of infiltration of deep structures.

Fine needle aspiration cytology (FNAC) increases the risk of implantation of endometrial tissue on the puncture site.

The post-excision or post-FNAC histopathological diagnosis is positive for endometriosis if two of the following three elements are detected: endometrial glands, endometrial stroma and hemosiderin laden macrophages. $(1,18)$

The treatment is a multidisciplinary one, the most used being the hormonal treatment as an association with the surgical or analgesic treatment. For abdominal wall endometriosis, surgery is the only curative treatment.

Preoperatively, intra-femoral injection of radioisotopes can be used to guide the excision of small foci of 


\section{CLINICAL ASPECTS}

endometriosis.

Sclerotherapy with ultrasound guided injection into the lesion and high intensity focused ultrasound ablation used preoperatively appear to reduce bleeding and limit the size of the resection and decrease the risk of recurrence.(19)

Endometriosis has a 1\% risk of malignancy.

$80 \%$ of malignancies occur in the ovary and $20 \%$ in other locations (including the abdominal wall). The most common types of malignancies are endometrial carcinoma (70\%), sarcoma (25\%) and clear cell carcinoma (5\%). Clear cell carcinoma and endometrial carcinoma have the lowest survival rate (44\% mortality in the months immediately following diagnosis). $(20,21)$

General surgeons often misdiagnose parietal enometriosis due to its rarity interpreting it as a tumour of another nature. Thus in a study that considered cases of endometriosis of the abdominal wall, treated by a general surgeon $55.55 \%$ of them they didn't suspected endometriosis preoperatively.(22,23)

Although it is a rare entity, general surgeons must also consider this type of tumour, so that the surgical strategy to be such as to avoid the implantation of endometrial cells, thus avoiding local recurrence.

\section{CONCLUSIONS}

Endometriosis of the abdominal wall is an increasingly common condition in the context of the proliferation of gynecological and obstetric procedures.

The diagnosis can be guided by clinical and imaging examination but is established by histologic exam.

Surgical removal of the endometrial implant remains the best therapeutic option, reducing the risk of recurrence or progression to malignancy.

\section{REFERENCES}

1. Song H, Lee S, Kim MJ, Shin JE, Lee DW, Lee HN. Abdominal wall mass suspected of endometriosis: clinical and pathologic features. Obstet Gynecol Sci. 2020;63(3):357-362.doi:10.5468/ogs.2020.63.3.357.

2. Emre A, Akubul S, YIlmaZ M, Bozdag Z. Laparoscopic Trocar Port Site Endometriosis: A Case Report and Brief Literature Review. Int Surg. 2012 Apr-Jun;97(2):135-139.

3. Khamechian $\mathrm{T}$, Alizargar J, Mazoochi $\mathrm{T}$ 5-Year data analysis of patients following abdominal wall endometrioma surgery BMC Women's Health. 2014;14:151.

4. Giudice C. Endometriosis The Lancet Volume. 2004:364:1789-1799.

5. Cojocari N, Ciutacu L, Lupescu I, Herlea V, Vasilescu ME, Sîrbu MP. Parietal Endometriosis: A Challenge for the General Surgeon. Chirurgia (Bucur). 2018;113(5):695703.doi:10.21614/chirurgia.113.5.695.

6. Thornton S, Woll J, Markfeld-Erol F, Hasenburg A, Proempeler $\mathrm{H}$, et al. Abdominal Wall Endometriosis after Gynaecological Interventions - A Cohort Study on Diagnostic and Treatment of Abdominal Wall Endometriosis. Int J Surg Res Pract, 2016. 3:044. 10.23937/2378-3397/1410044

7. Nominato NS, Prates LF, Lauar I, Morais J, Maia L, Geber $\mathrm{S}$. Caesarean section greatly increases risk of scar endometriosis. Eur J Obstet Gynecol Reprod Biol. 2010;152(1):83-85. doi:10.1016/j.ejogrb.2010.05.001.

8. Kumar Saroj J, Prakash B, Sharma A. Intramuscular Abdominal Wall Endometriosis Away from Caesarean Scar; A Diagnostic Dilemma for Surgeons. AJCRS. 2019;2:1-4.

9. Paşalega M, Mirea C, Vîlcea ID, et al. Parietal abdominal endometriosis following Cesarean section. Rom J Morphol Embryol. 2011;52(1 Suppl):503-508.

10. Bektaş H, Bilsel Y, Sari YS, et al. Abdominal wall endometrioma; a 10-year experience and brief review of the literature. J Surg Res. 2010;164(1):e77-e81. doi:10.1016/j.jss.2010.07.043.

11. Cozzolino Mauro, Magnolfi, S, Corioni, S, Moncini, D, Mattei, A. Abdominal Wall Endometriosis on the Right Port Site After Laparoscopy: Case Report and Literature Review. The Ochsner Journal. 2015;15:251-5.

12. Mizutani K, Nakanishi K, Hiraki, Ono H, Ozaki K, Nagano T. A case of abdominal wall endometriosis after appendectomy. Journal of Japan Surgical Association. 2012;73(4):993-996.

13. Ducarme G, Uzan M, Poncelet C. Endometriosis mimicking hernia recurrence. Hernia. 2007;11(2):175-177. doi:10.1007/s10029-006-0159-2.

14. Blumenthal R, Samoszuk M, Taylor A, Brown G, Alisauskas R, Goldenberg D. Degranulating Eosinophils in Human Endometriosis. The American journal of pathology. 156. 1581-8.(2000) 10.1016/S0002-9440(10)65030-4.

15. Esquivel-Estrada V, Briones-Garduño JC, MondragónBallesteros R. Implante de endometriosis en cicatriz de operación cesárea [Endometriosis implant in cesarean section surgical scar]. Cir Cir. 2004;72(2):113-115.

16. Savelli L, Manuzzi L, Di Donato N, et al. Endometriosis of the abdominal wall: ultrasonographic and Doppler characteristics. Ultrasound Obstet Gynecol. 2012;39(3):336-340. doi:10.1002/uog.10052.

17. Vagholkar K, Vagholkar S. Abdominal Wall Endometrioma: A Diagnostic Enigma-A Case Report and Review of the Literature. Case Rep Obstet Gynecol. 2019;2019:6831545. Published 2019 Mar 26. doi: $10.1155 / 2019 / 6831545$.

18. Gupta RK. Fine-needle aspiration cytodiagnosis of endometriosis in cesarean section scar and rectus sheath mass lesions - a study of seven cases. Diagn Cytopathol.2008;36(4):224-226.doi:10.1002/dc.20797.

19. Vitral GSF, Salgado HC, Rangel JMC. Use of radioguided surgery in abdominal wall endometriosis: An innovative approach. World J Nucl Med. 2018;17(3):204206.doi:10.4103/wjnm.WJNM_47_17.

20. Kajiyama H, Suzuki S, Yoshihara M, et al. Endometriosis and cancer. Free Radic Biol Med. 2019;133:186-192. doi:10.1016/j.freeradbiomed. 2018.12.015.

21. Carsote M, Terzea DC, Valea A, Gheorghisan-Galateanu AA. Abdominal wall endometriosis (a narrative review). Int J Med Sci. 2020;17(4):536-542. Published 2020 Feb 10. doi:10.7150/ijms.38679.

22. Oh EM, Lee WS, Kang JM, Choi ST, Kim KK, Lee WK. A Surgeon's Perspective of Abdominal Wall Endometriosis at a Caesarean Section Incision: Nine Cases in a Single Institution. Surg Res Pract. 2014;2014:765372. doi:10.1155/2014/765372.

23. Horton JD, Dezee KJ, Ahnfeldt EP, Wagner M. Abdominal wall endometriosis:a surgeon's perspective and review of 445 cases. Am J Surg. 2008;196(2):207-212. doi:10.1016/j.amjsurg.2007.07.035. 